\title{
Fifteen years in the evaluation of extrapleural pneumonectomy: Lessons to be learned
}

\author{
Tom Treasure, MD, MS, FRCS, FRCP, ${ }^{a}$ and Fergus Macbeth, MA, DM, FRCP ${ }^{b}$
}

See related article on pages $1374-81$.

From 2001 to 2010, a total of 447 patients were recorded in Brigham and Women's Hospital (BWH) International Mesothelioma Program Patient Data Registry as having had extrapleural pneumonectomy (EPP). Patterns of recurrence among 169 (38\%) who had undergone initial EPP are reported. The remaining $62 \%$ of patients, treated initially with chemotherapy, were excluded as "a distinct cohort with poorer prognosis." Median survival was 15 months for the EPP-first patients, and evidently shorter ${ }^{1}$ for the remaining $62 \%$.

\section{A 15-YEAR ERA OF EPP EVALUATION}

In 1999 there were 3 landmark publications:

- Peto and colleagues ${ }^{2}$ alerted us to an epidemic of mesothelioma in Europe, and we have seen the prediction fulfilled;

- BWH reported ${ }^{3} 19$ months median survival in 176 hospital survivors of trimodal therapy with EPP, raising hopes of survival benefit;

- Butchart, ${ }^{4}$ who had reported an earlier experience, proposed that EPP, within multimodality treatment, should be the subject of multicenter trials.

The subsequent 15 years saw intense activity in the treatment of mesothelioma.

\section{Understanding Efficacy and Effectiveness}

When used in evaluating treatments, efficacy and effectiveness have distinct meanings. ${ }^{5}$ If intensity-modulated radiotherapy resulted in no recurrence within the radiation field, or heated intra-operated chemotherapy reduced local recurrence, that would be evidence of efficacy (Figure 1). When used in combination with EPP, intensity-modulated

\footnotetext{
From the Clinical Operational Research Unit, ${ }^{a}$ University College London, London; and Department of Oncology, ${ }^{\mathrm{b}}$ Wales Cancer Trials Unit, Cardiff University, Cardiff, United Kingdom.

Disclosures: Authors have nothing to disclose with regard to commercial support.

Received for publication Oct 18, 2014; accepted for publication Oct 18, 2014; available ahead of print Nov 15, 2014.

Address for reprints: Tom Treasure, MD, MS, FRCS, FRCP, Clinical Operational Research Unit, University College London, Mathematics: Clinical Operational Research Unit, 4 Taviton Street, London WC1 H0BT, United Kingdom (E-mail: tom.treasure@gmail.com).

J Thorac Cardiovasc Surg 2015;149:1382-3

0022-5223/\$36.00

Copyright (c) 2015 by The American Association for Thoracic Surgery

http://dx.doi.org/10.1016/j.jtcvs.2014.10.083
}

radiotherapy was associated with 10 months median survival (intention to treat). ${ }^{6}$ Heated intra-operated chemotherapy with EPP gave a median survival of 13 months, 6 months shorter than before its introduction. ${ }^{3,7}$ Neither demonstrated effectiveness in lengthening survival in association with EPP. But how could we determine the effectiveness of EPP itself?

\section{Seeing the Signal Within the Noise: What Should Be the Comparator for EPP?}

When a mechanistically plausible intervention visibly, quickly, and reproducibly alters the course of events, we have traditionally relied on observation alone and should continue to do so, but with an appropriate degree of caution. ${ }^{8,9}$ Surgeons know examples: relieving tension pneumothorax, controlling exsanguinating hemorrhage, removing a cataract.

After Butchart's report ${ }^{4}$ in 1976, EPP had been dismissed because of a consistent pattern of early recurrence. To be reconsidered as part of multimodal treatment, what should be the comparator? Clearly not the 7 months median survival among patients fit only for supportive care. ${ }^{1}$ Only a small minority of patients are ever candidates for $\mathrm{EPP},{ }^{10}$ and to receive 1,2 , or more other treatments, patients had to have a better than average inherent prognosis, introducing immortal time bias. ${ }^{11}$ Being a survivor is an essential inclusion criterion for getting multimodal treatment; when survival is the primary outcome of interest, this will confound multivariate analyses. ${ }^{12-14}$

\section{Intention to Treat, External and Impartial Monitoring, and Independent Analysis}

It is important to recognize the principle of a "fair test." ${ }^{15}$ The comparison should be made with patients who are as similar as possible, accounting for known and unknown variables, ideally a randomly assigned control group. A well conducted randomized controlled trial requires an externally peer-reviewed protocol. It should be multicenter, impartially run, scrupulously monitored, and analyzed on intention to treat, which is how the mesothelioma and radical surgery (MARS) trial was set up. ${ }^{16,17} \mathrm{~A}$ cohort of patients was assessed as suitable for EPP, but were randomly assigned to not have it. Their median survival was 19.5 months. ${ }^{18,19}$

\section{Patient-Reported Outcomes}

Quality of life and other patient-reported outcomes are not reported in the BWH study. In Lionel Shriver's novel So Much for That,${ }^{20}$ the husband of a woman with peritoneal 


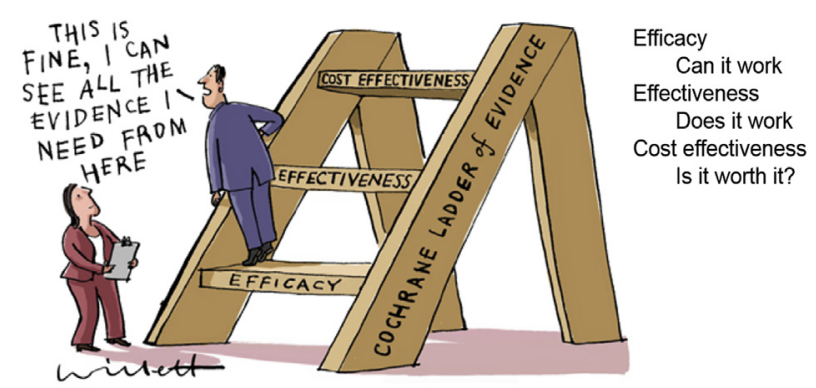

FIGURE 1. The Cochrane ladder of evidence. Reprinted with permission. ${ }^{5}$

mesothelioma, approaching the end of life and their \$2 million retirement fund, asks: "So what exactly did we buy? How much time?" The doctor replies: "Oh, I bet we've probably extended her life a good three months." The husband returns: "No, I'm sorry Dr. Goldman. They were not a good three months." We do not have the evidence that EPP in multimodality treatment buys time, ${ }^{21}$ and what time our patients do have should not be made worse by our treatments. We know that EPP is associated with a high rate of complications. ${ }^{22}$ In nonrandomized but well considered comparative studies, EPP resulted in more complications, poorer quality of life, ${ }^{23}$ and shorter survival than lung-sparing surgery. ${ }^{24}$

\section{THE WAY AHEAD}

These have been 15 years in which there have been 2 randomized trials. ${ }^{18,25}$ There should have been and still should be more. Otherwise, with a disease as variable as mesothelioma, with many possible but untested treatments, given in combination or in sequence, we will never see the signal for the noise. We need to distinguish between efficacy of individual elements of treatment and clinical effectiveness of treatment programs. To refine the questions and design the studies, we need independent analysis of all the data, rather than institutionally selected subsets. We need multicenter trials, impartially conducted, monitored, and analyzed. ${ }^{10,26}$

\section{References}

1. Baldini E. Updated patterns of failure following multimodality therapy for malignant pleural mesothelioma. J Thorac Cardiovasc Surg. In press.

2. Peto J, Decarli A, La Vecchia C, Levi F, Negri E. The European mesothelioma epidemic. Br J Cancer. 1999;79:666-72.

3. Sugarbaker DJ, Flores RM, Jaklitsch MT, Richards WG, Strauss GM, Corson JM, et al. Resection margins, extrapleural nodal status, and cell type determine postoperative long-term survival in trimodality therapy of malignant pleural mesothelioma: results in 183 patients. J Thorac Cardiovasc Surg. 1999;117:54-63.

4. Butchart EG. Contemporary management of malignant pleural mesothelioma. Oncologist. 1999;4:488-500.
5. Jarvinen TL, Sievanen H, Kannus P, Jokihaara J, Khan KM. The true cost of pharmacological disease prevention. BMJ. 2011;342:d2175.

6. Rice DC, Stevens CW, Correa AM, Vaporciyan AA, Tsao A, Forster KM, et al. Outcomes after extrapleural pneumonectomy and intensity-modulated radiation therapy for malignant pleural mesothelioma. Ann Thorac Surg. 2007;84: 1685-92.

7. Tilleman TR, Richards WG, Zellos L, Johnson BE, Jaklitsch MT, Mueller J, et al. Extrapleural pneumonectomy followed by intracavitary intraoperative hyperthermic cisplatin with pharmacologic cytoprotection for treatment of malignan pleural mesothelioma: a phase II prospective study. J Thorac Cardiovasc Surg. 2009; 138:405-11.

8. Glasziou P, Chalmers I, Rawlins M, McCulloch P. When are randomised trials unnecessary? Picking signal from noise. BMJ. 2007;334:349-51.

9. Fiorentino F, Treasure T. Pulmonary metastasectomy: are observational studies sufficient evidence for effectiveness? Ann Thorac Surg. 2013;96:1129-31.

10. Datta A, Smith R, Fiorentino F, Treasure T. Surgery in the treatment of malignant pleural mesothelioma: recruitment into trials should be the default position. Tho$\operatorname{rax} .2014 ; 69: 194-7$.

11. Levesque LE, Hanley JA, Kezouh A, Suissa S. Problem of immortal time bias in cohort studies: example using statins for preventing progression of diabetes. BMJ. 2010;340:b5087.

12. Treasure T, Utley M. Ten traps for the unwary in surgical series: a case study in mesothelioma reports. J Thorac Cardiovasc Surg. 2007;133:1414-8.

13. Flores RM, Zakowski M, Venkatraman E, Krug L, Rosenzweig K, Dycoco J, et al. Prognostic factors in the treatment of malignant pleural mesothelioma at a large tertiary referral center. $J$ Thorac Oncol. 2007;2:957-65.

14. Utley M, Fiorentino F, Treasure T. Obtaining an upper estimate of the survival benefit associated with surgery for mesothelioma. Eur J Cardiothorac Surg. 2010;38:241-4.

15. Evans I, Thornton H, Chalmers I, Glasziou P. Testing Treatments. 2nd ed. London: Pinter \& Martin; 2011.

16. Treasure T, Waller D, Swift S, Peto J. Radical surgery for mesothelioma. BMJ 2004;328:237-8.

17. Treasure T, Waller D, Tan C, Entwisle J, O'Brien M, O'Byrne K, et al. The mesothelioma and radical surgery randomized controlled trial: the MARS feasibility study. J Thorac Oncol. 2009;4:1254-8.

18. Treasure T, Lang-Lazdunski L, Waller D, Bliss JM, Tan C, Entwisle J, et al. Extra-pleural pneumonectomy versus no extra-pleural pneumonectomy for patients with malignant pleural mesothelioma: clinical outcomes of the mesothelioma and radical surgery (MARS) randomised feasibility study. Lancet Oncol. 2011; 12:763-72.

19. Treasure T, Utley M, O'Byrne K. MARS: a sense of perspective and an inconvenient truth. J Thorac Oncol. 2013;8:e48-9.

20. Shriver L. So Much for That. New York: Harper Collins; 2010.

21. Lee YC. Surgical resection of mesothelioma: an evidence-free practice. Lancet. 2014;384:1080-1.

22. Sugarbaker DJ, Jaklitsch MT, Bueno R, Richards W, Lukanich J, Mentzer SJ, et al. Prevention, early detection, and management of complications after 328 consecutive extrapleural pneumonectomies. J Thorac Cardiovasc Surg. 2004; 128:138-46.

23. Rena O, Casadio C. Extrapleural pneumonectomy for early stage malignant pleural mesothelioma: A harmful procedure. Lung Cancer. 2012;77:151-5.

24. Flores RM, Pass HI, Seshan VE, Dycoco J, Zakowski M, Carbone M, et al. Extrapleural pneumonectomy versus pleurectomy/decortication in the surgical management of malignant pleural mesothelioma: results in 663 patients. $J$ Thorac Cardiovasc Surg. 2008;135:620-6.

25. Rintoul RC, Ritchie AJ, Edwards JG, Waller DA, Coonar AS, Bennett M, et al. Efficacy and cost of video-assisted thoracoscopic partial pleurectomy versus talc pleurodesis in patients with malignant pleural mesothelioma (MesoVATS): an open-label, randomised, controlled trial. Lancet. 2014;384:1118-27.

26. Treasure T, Dusmet M, Fiorentino F, Lim E, Waller D, Lees B. Surgery for malignant pleural mesothelioma: why we need controlled trials. Eur J Cardiothorac Surg. 2014;45:591-2. 